\title{
COMPUTATION OF RELATIVE INTEGRAL BASES FOR ALGEBRAIC NUMBER FIELDS
}

\author{
MAHMOOD HAGHIGHI \\ Department of Computer Science \\ Bradley Unfversity \\ Peoria, IL 61625
}

(Received March 2, 1987 and in revised form September 21, 1987)

ABSTRACT. At first we are given conditions for existence of relative integral bases for extension $(K ; k)=n$. Then we will construct relative integral bases for extensions $0_{\mathrm{K}_{6}}(\sqrt[6]{-3}) / 0_{\mathrm{k}_{2}}(\sqrt{-3}), \mathrm{O}_{\mathrm{K}_{6}}(\sqrt[6]{-3}) / 0_{\mathrm{k}_{3}}(\sqrt[3]{-3}), 0_{\mathrm{K}_{6}}(\sqrt[6]{-3}) / \mathrm{z}$.

KEY WORDS AND PHRASES. Integral Bases and Principal Ideal.

1980 AMS SUBJECT CLASSIFICATION CODE. 115.

1. EXISTENCE OF A RELATIVE INTEGRAL BASES.

The following criterion has been shown in [1] for existence of a Relative Integral Bases, for any finite extension $\mathrm{K} / \mathrm{k}$.

THEOREM 1.1. Let $(\mathrm{K} ; \mathrm{k})=\mathrm{n}$, and 1 et $\mathrm{h}_{\mathrm{k}}$ be an odd integer, then $\mathrm{O}_{\mathrm{K}}$ has a "relative integral bases" over $0_{k} \leftrightarrow d_{K / k}$ is a principal ideal. See also [2].

COROLLARY 1.2. If $0_{K}=$ P.I.D., then $h_{k}=1$ and $d_{K / k}=$ P.I. Therefore for every finite extension of $k$ where $0_{k}=$ P.I.D., a relative integral bases exists.

Let $\mathrm{k}_{1}=\mathrm{Q}, \mathrm{k}_{2}=\mathrm{Q}(\sqrt{-3}), \mathrm{k}_{3}=\mathrm{Q}(\sqrt[3]{-3}), \mathrm{K}_{6}=\mathrm{Q}(\sqrt[6]{-3})$. Since $\mathrm{h}_{\mathrm{k}_{1}}=\mathrm{h}_{\mathrm{k}_{2}}=\mathrm{h}_{\mathrm{k}_{3}}=1$, so $0_{K_{1}}, O_{K_{2}}, O_{K_{3}}$ are P.I.D. and then by corollary 1.2 , relative integral bases for extensions $\mathrm{k}_{6} / \mathrm{k}_{1}, \mathrm{k}_{6} / \mathrm{k}_{2}, \mathrm{k}_{6} / \mathrm{k}_{3}$ exists.

Now, we will compute the relative discriminant for the extensions. Let $(\mathrm{K} ; \mathrm{k})=\mathrm{n}$ and for some $\theta \in K, O_{K}=o_{k}(\theta)$ and $\theta$ satisfies an equation $F(\theta)=0$ of degree $n$. Then $D_{K / k}=\left(F(\theta)=\Pi\left(\theta-\theta^{(t)}\right)\right.$, where $\theta, \theta^{(1)}, \theta^{(2)}, \ldots, \theta^{(n)}$ are conjugates [3].

Since extensions $\mathrm{K}_{2} / \mathrm{K}_{1}, \mathrm{~K}_{3} / \mathrm{K}_{1}$ have discriminant divisible by 3 [3], by theorem in [3] discriminants $\mathrm{k}_{6} / \mathrm{k}_{2}, \mathrm{~K}_{6} / \mathrm{k}_{3}, \mathrm{~K}_{6} / \mathrm{k}_{1}$ are also divisible by 3 and 3 is completely ramified in $\mathrm{k}_{1}, \mathrm{k}_{2}, \mathrm{k}_{3}$.

For extension $\mathrm{k}_{6} / \mathrm{k}_{2}, \theta=6 \sqrt{-3}$ we therefore have:

$$
\begin{aligned}
& \mathrm{D}_{\mathrm{K}_{6} / \mathrm{k}_{2}}=\left(\theta-\theta^{(1)}\right)\left(\theta-\theta^{(2)}\right)=\left(\sqrt[6]{-3}-\rho^{6 \sqrt{-3}}\right)\left(\sqrt[6]{-3}-\rho^{2} \cdot 6 \sqrt{-3}\right), \\
& \mathrm{D}_{\mathrm{K}_{6} / \mathrm{k}_{2}}=(-3)^{4 / 3} \text { for } \rho=\frac{-1+\sqrt{-3}}{2} \text {. By the definition in [4], } \\
& \mathrm{d}_{\mathrm{K}_{6} / \mathrm{k}_{2}}=\mathrm{N}_{\mathrm{K}_{6} / \mathrm{k}_{2}}\left(\mathrm{D}_{\mathrm{K}_{6} / \mathrm{k}_{2}}\right)=(-3)^{4} .
\end{aligned}
$$


For extension $\mathrm{K}_{6} / \mathrm{k}_{3}, \theta=\sqrt[6]{-3}, \mathrm{D}_{\mathrm{K}_{6} / \mathrm{k}_{3}}=\left(\theta-\theta^{(1)}\right)=(-3)^{1 / 6}$, then $\mathrm{d}_{\mathrm{K}_{6} / \mathrm{k}_{3}}=(-3)^{1 / 2}$. By theorem in [4], $\mathrm{D}_{\mathrm{K}_{6} / \mathrm{k}_{1}}=\mathrm{D}_{\mathrm{K}_{6} / \mathrm{k}_{2}} \cdot \mathrm{D}_{\mathrm{k}_{2} / \mathrm{k}_{1}}=(-3)^{4 / 3} \cdot(-3)^{1 / 2}=(-3)^{11 / 6}$, then
$=(-3)^{11}$. $\mathrm{d}_{\mathrm{K}_{6} / \mathrm{k}_{1}}=(-3)^{11}$.

Now we will construct relative integral bases for the extensions. See also [5] for associated work.

$$
\begin{aligned}
& \text { For } \left.\mathrm{k}_{3} / \mathrm{k}_{1}, \mathrm{o}_{\mathrm{K}_{3}}=(1, \sqrt[3]{-3}, 3 \sqrt{(-3})^{2}\right) \cdot \mathrm{z},[3] . \\
& \text { For } \mathrm{k}_{2} / \mathrm{k}_{1}, \mathrm{o}_{\mathrm{K}_{2}}=\left(1, \frac{1+\sqrt{-3}}{2}\right) \cdot \mathrm{z},[3] .
\end{aligned}
$$

2. RELATIVE INTEGRAL BASES FOR $0_{6}(\sqrt[6]{-3}) / 0_{2}(\sqrt{-3})$.

Let $0_{6}=(1, \alpha, \beta) 0_{2}$ for $\alpha, \beta$ in $0_{6}$. By theorem in $[6]$, disc $(1, \alpha, \beta)=d_{k_{6} / k_{2}}$,

$$
\operatorname{disc}(1, \alpha, \beta)=\left|\begin{array}{ccc}
1 & \rho \alpha & \rho^{2} \beta
\end{array}\right|=d_{k_{6} / k_{2}}=(-3)^{4} \text {. }
$$

Now $\alpha^{2} \beta^{2}\left(3 \rho^{2}-3 \rho\right)^{2}=(-3)^{4}$ and from here $\alpha \cdot \beta=\sqrt{-3}$.

We may take $\alpha=6 \sqrt{-3}$ and $\beta=6 \sqrt{(-3)^{2}}$, because they satisfy an $\alpha \cdot \beta=\sqrt{-3}$ and they are in $\mathrm{O}_{6}$.

Since $\mathrm{N}_{6 / 3}(\alpha)=\sqrt[3]{-3}$ and $\mathrm{N}_{6 / 3}(\beta)=\sqrt[3]{(-3)^{2}}$ are in $0_{3}$, we have:

$$
0_{6}=\left(1,6 \sqrt{-3}, 6 \sqrt{(-3)^{2}}\right) 0_{2} .
$$

3. RELATIVE INTEGRAL BASES FOR $0_{6}(\sqrt[6]{-3}) / 0_{3}(\sqrt[3]{-3})$.

Let $0_{6}=(1, \alpha) 0_{3}$ for $\alpha \varepsilon 0_{6}$. Again by theorem [6]

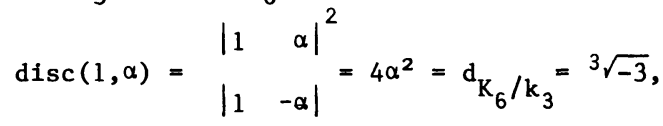

Note $\alpha=\frac{\sqrt[6]{-3}}{2} \neq 0_{6}$, because $\mathrm{N}_{6 / 3}(\alpha)=\frac{6 \sqrt{-3}}{2} \frac{-\sqrt[6]{-3}}{2}=\frac{-3 \sqrt{-3}}{4} \varepsilon 0_{3}$. Hence, $(1, \alpha)$ is not a relative integral bases.

We define $\alpha=\frac{\beta+\sqrt[3]{-3}}{2}$ for $\beta \varepsilon 0_{3}$ such that $N_{6 / 3}(\alpha)$ is divisible by $2.2=4$ and $\alpha \varepsilon 0_{6}$. If we take $\beta=\sqrt[3]{(-3)^{2}} \in 0_{3}$, it satisfies the conditions, this is because

$$
\frac{\beta+6 \sqrt{-3}}{2} \cdot \frac{\beta-6 \sqrt{-3}}{2}=\frac{3 \sqrt{(-3)^{4}-6 \sqrt{(-3)^{2}}}}{4}=3 \sqrt{-3} \varepsilon 0_{3} \text {, by theorem [6], }
$$

Also, $\operatorname{disc}(1, \alpha)=\mathrm{d}_{\mathrm{k}_{6} / \mathrm{k}_{3}}$, so that:

$$
0_{6}=\left(1, \frac{3 \sqrt{(-3)^{2}}+6 \sqrt{-3}}{2}\right) \cdot 0_{3} \text {. }
$$

4. RELATiVE INTEGRAL BASES FOR $0_{6}(\sqrt[6]{-3}) / \mathrm{z}$.

Since $K_{6}=Q(\sqrt[6]{-3})$, at first we start by:

$$
0_{6}=\left(1, \theta, \theta^{2}, \theta^{3}, \theta^{4}, \theta^{5}\right) \mathrm{z}
$$

Let $\theta=6 \sqrt{-3} \varepsilon 0_{6}$. Since $\operatorname{disc}\left(1, \theta, \theta^{2}, \theta^{3}, \theta^{4}, \theta^{5}\right)=2^{2} \cdot 2^{2} \cdot 2^{2} \cdot d_{K_{6}} / k_{1}$, we can apply 
theorem [3] in order to cancel out $2^{2} \cdot 2^{2} \cdot 2^{2}$ and generate a new bases.

We will build a new bases $\alpha_{1}^{*}=\left\{\alpha_{1}: 0 \leqq 1 \leqq 5\right\}$. By the theorem [3] we check which $\alpha_{i}$ is going to be changed. $\alpha_{0}{ }^{*}=\alpha_{0} / 2=1 / 2 \notin 0_{6}$. Thus there is no change for the first bases element $\alpha_{0}=1$.

$\alpha_{1}{ }^{*}=\frac{g_{1} \alpha_{0}+\alpha_{1}}{2}=\frac{g_{1} \alpha_{0}+\theta}{2}$ for $0 \leqq g_{i} \leqq 1$. For any value of $g_{1}, \alpha_{1}$ is not in $0_{6}$.

This is because

$\mathrm{N}_{6 / 3}\left(\alpha_{1}{ }^{*}\right)=\frac{1+6 \sqrt{-3}}{2} \cdot \frac{1-6 \sqrt{-3}}{2}=\frac{1-3 \sqrt{-3}}{4} \notin 0_{3}$ and also since $N_{6 / 3}(\theta / 2) \notin 0_{3}$, so there is no change for $\alpha_{1}$.

$\alpha_{2}{ }^{*}=\frac{g_{1} \alpha_{0}+g_{2} \alpha_{1}+\alpha_{2}}{2}$ for $0 \leqq g_{1} \leqq 1$. For any value of $g_{1}, \alpha_{2}{ }^{*} 0_{6}$, then there will be no change for $\alpha_{2}$.

$\alpha_{3}{ }^{*}=\frac{g_{1} \alpha_{0}+g_{2} \alpha_{1}+g_{3} \alpha_{2}+\alpha_{3}}{2}$ for $0 \leqq g_{1} \leqq 1$. In this case for $g 1=g 2=g^{3}=1$, $\alpha_{3}^{*}=\sqrt[6]{(-3)^{4}} \varepsilon 0_{6}$. This is because:

$\alpha_{3}{ }^{*}=\frac{1+\sqrt[6]{(-3)^{3}}}{2} \cdot \frac{1-\sqrt[6]{(-3)^{3}}}{2}=\frac{1-\sqrt[6]{(-3)^{6}}}{4}=1 \varepsilon 0_{3}$, and for other values

of $g_{1}, \alpha_{3}^{*} \neq 0_{6}$.

$\alpha_{4}{ }^{*}=\frac{g_{1} \alpha_{0}+g_{2} \alpha_{1}+g_{3} \alpha_{2}+g_{4} \alpha_{3}^{*}+\alpha_{4}}{2}$. In this case for $g 2=g 4=1$,

$\alpha_{4}{ }^{*}=\frac{6 \sqrt{-3}+\sqrt[6]{(-3)^{4}}}{2} \varepsilon 0_{6}$. This is because

$\mathrm{N}_{6 / 3}\left(\alpha_{4}{ }^{*}\right)=\frac{\sqrt[6]{-3}+\sqrt[6]{(-3)^{4}}}{2} \cdot \frac{6 \sqrt{-3}-\sqrt[6]{(-3)^{4}}}{2}=\frac{4 \cdot \sqrt[3]{-3}}{4} \varepsilon 0_{3}$, and for other $g_{i}, \alpha_{4}{ }^{*} \notin 0_{6}$.

$\alpha_{5}{ }^{*}=\frac{g_{1} \alpha_{0}+g_{2} \alpha_{1}+g_{3} \alpha_{2}+g_{4} \alpha_{3}^{*}+g_{5} \alpha_{4}{ }^{*}+\alpha_{5}}{2}$, for $g_{2}=g_{5}=1$,

$\alpha_{5}{ }^{*}=\frac{\sqrt[6]{(-3)^{2}}+\sqrt[6]{(-3)^{5}}}{2} \varepsilon 0_{6}$. This is because $\mathrm{N}_{6 / 3}\left(\alpha_{5}{ }^{*}\right) \varepsilon 0_{3}$, and for other values of $g_{1}, \alpha_{5} * 0_{6}$. This last assertion is since $\operatorname{disc}\left(\alpha_{0}, \alpha_{1}, \alpha_{2}, \alpha_{3}{ }^{*}, \alpha_{4}{ }^{*}, \alpha_{5}{ }^{*}\right)=\frac{2^{2} \cdot 2^{2} \cdot 2^{2}}{2^{2} \cdot 2^{2} \cdot 2^{2}} \cdot d_{\mathrm{K} 6 / \mathrm{kl}}$, and each $\alpha_{1}, \alpha_{1}{ }^{*}$ are in $0_{6}$, then by theorem [6].

$0_{6}=\left(1,6 \sqrt{-3}, \sqrt[6]{(-3)^{2}}, \frac{1+\sqrt[6]{(-3)^{3}}}{2}, \frac{6 \sqrt{-3}+\sqrt[6]{(-3)^{4}}}{2}, \frac{6 \sqrt{(-3)^{2}}+\sqrt[6]{(-3)^{5}}}{2}\right) \cdot \mathrm{z}$. 


\section{REFERENCES}

1. NARIEWICZ, W. Elementary and Analytic Theory of Algebraic Numbers, Pwin, Warsaw, 1976.

2. ARTIN, E. Questions de Base Minimal dans la Theorie des Nombres Algebriques, National de la Recherche Scientifiques XXIV, (1950), 19-20.

3. COHN, H. A Classical Invitation to Algebraic Numbers and Class Field Theory, Springer-Verlag, New York, 1978.

4. COHN, H. Introduction to the Construction of Class Fields, Cambridge University Press, New York, 1985.

5. HAGHIGHI, M. Relative Integral Bases for Algebraic Number Fields, Internat. J. Math. and Math. Sci. 9 (1986), 97-104.

6. RIBENBOIM, P. Algebraic Number Theory, John Wiley and Sons, New York, 1972. 


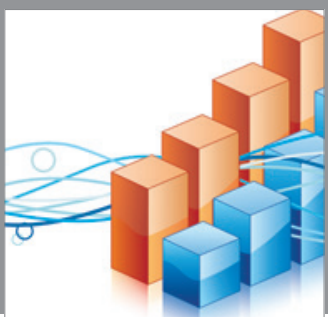

Advances in

Operations Research

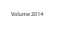

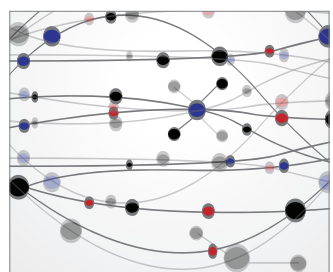

\section{The Scientific} World Journal
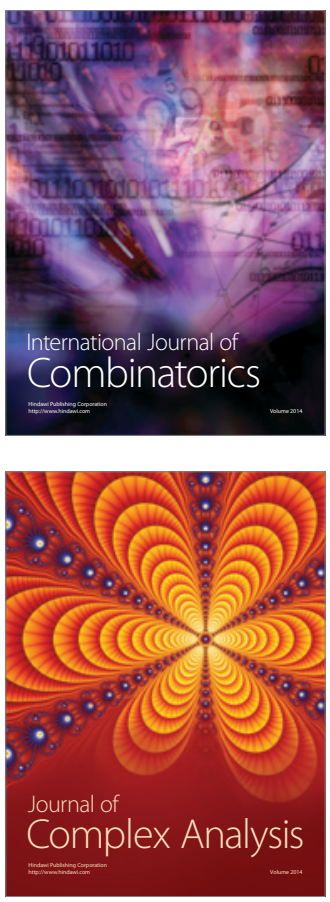

International Journal of

Mathematics and

Mathematical

Sciences
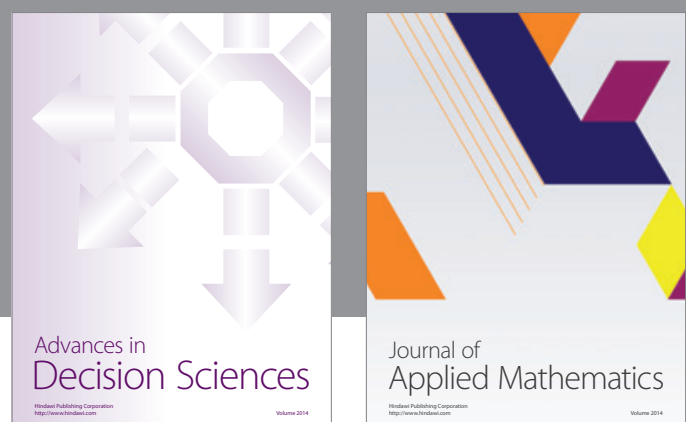

Journal of

Applied Mathematics
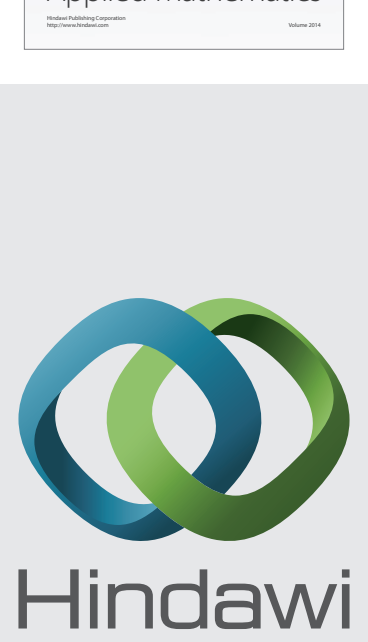

Submit your manuscripts at http://www.hindawi.com
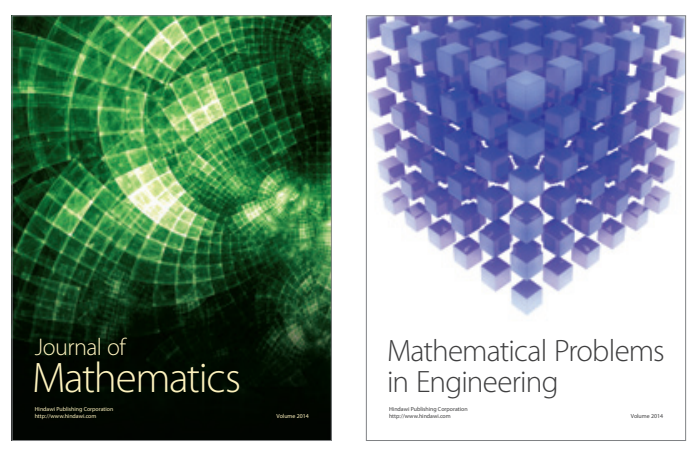

Mathematical Problems in Engineering
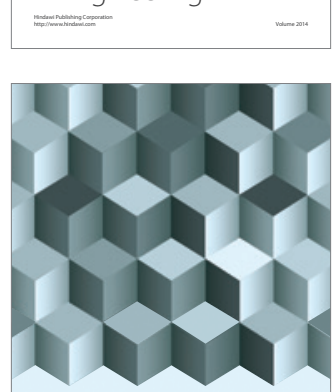

Journal of

Function Spaces
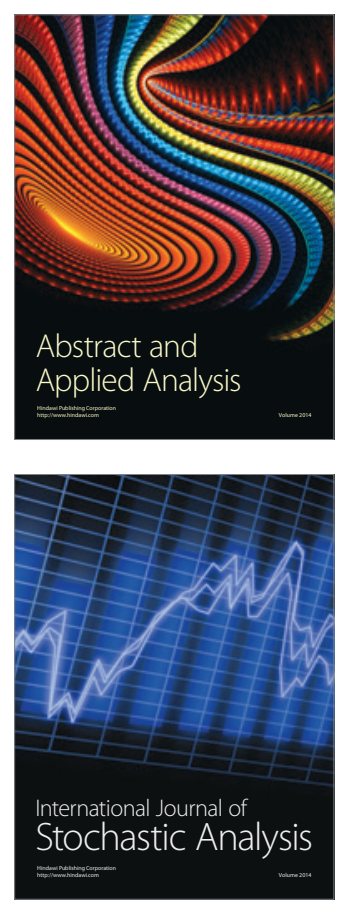

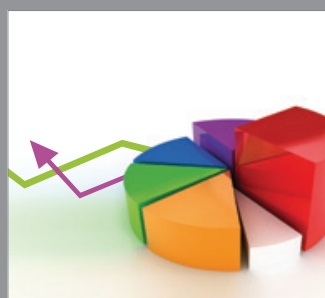

ournal of

Probability and Statistics

Promensencen
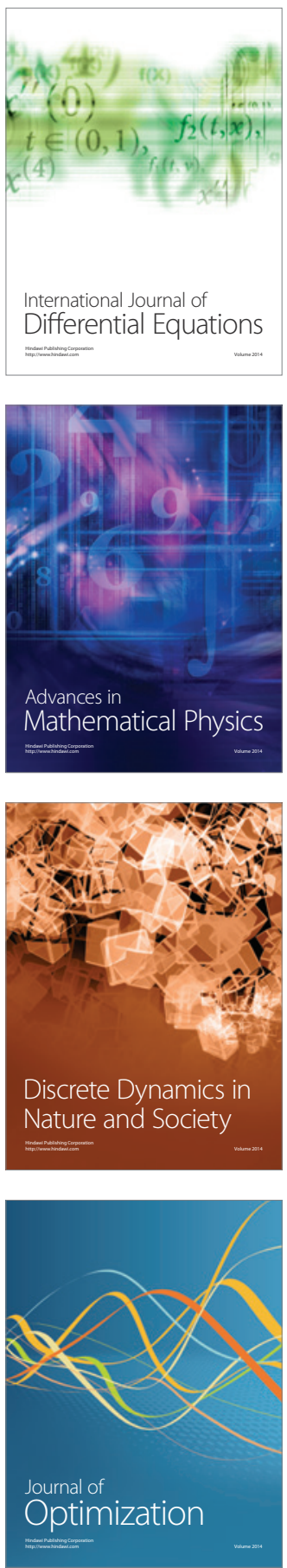